\title{
Seroepidemiología de la toxoplasmosis en una comunidad indígena Yucpa de la Sierra de Perijá, Estado Zulia, Venezuela
}

\author{
O delis Díaz-Suárez, Jesús Estévez $M$, María G arcía Pa, \\ Rosita Cheng-N g', José Araujo Ba, Marina G arcía PC. \\ Prevalence of antibodies against \\ Toxoplasma gondii in a Yucpa \\ Amerindian community of Venezuela
}

Background: There is a high rate of Toxoplasma gondii infection worldwide. In Latin America the rate is as high as 65\% in some populations. Aim: To measure the prevalence of antibodies against Toxoplasma gondii in a native Yucpa community in Venezuela. Subjects and method: Total serum antibodies measured by indirect hemagglutination and IgM antibodies by ELISA were measured in 94 Yucpa subjects (49 males), aged from 3 months to 100 years. Results: The overall prevalence of infection was $63 \%$. Fifty nine subjects had total antibodies and 14 had IgM antibodies. No significant differences by age or sex, were observed in the proportion of subjects with positive total or IgM antibodies. Conclusions: The studied individuals had a high prevalence of Toxoplasma gondii infection (Rev Méd Chile 2003; 131: 1003-10).

(Key Words: Antibodies, protozoan; Toxoplasma: Toxoplasmosis)

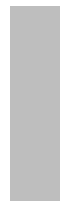

Recibido el 20 de agosto, 2002. Aceptado en versión corregida el 17 de julio, 2003.

Instituto de Investigaciones Clínicas “Dr. Américo Negrette”. Facultad de Medicina. La Universidad del Zulia. Maracaibo, Estado Zulia, Venezuela.

aLicenciado en Biología.

bLicenciada en Bioanálisis.

${ }^{\mathrm{C}}$ Técnico de laboratorio.

$E^{1}$ agente causal de la toxoplasmosis, Toxoplasma gondii, es un protozoo distribuido mundialmente ${ }^{1}$, considerado uno de los parásitos más frecuentes del ser humano ${ }^{2}$. La transmisión

Correspondencia a: Dra. Odelis Díaz de Suárez. Instituto de Investigaciones Clínicas "Dr. Américo Negrette". Apartado 1151, Maracaibo 4001-A, Venezuela. Teléfono: 58-2617597247 - 58-261-7597248. E mail: majuodelis@yahoo.com natural ocurre generalmente a través de ooquistes presentes en suelos contaminados con las heces de gatos infectados o por la ingestión de carne cruda contaminada con quistes tisulares. Otras formas de transmisión, menos frecuentes, son a través de la placenta y por el trasplante de órganos ${ }^{2,3}$.

Las encuestas serológicas efectuadas en diferentes países, indican un rango de infección de 40 a $50 \%$ en individuos adultos entre los 30 y los 40 años de edad ${ }^{2}$. 
La infección con T gondii se encuentra ampliamente distribuida en Latinoamérica, con anticuerpos anti $\mathrm{T}$ gondii detectables hasta en $65 \%$ en la población ${ }^{4}$. Se han descrito elevadas prevalencias en países como: Chile ${ }^{5,6}$, Brasil $^{7}$, Ecuador $^{8}$, Panamá $^{4}$, Costa Rica ${ }^{10}$, México $^{11}, \mathrm{Cuba}^{12}$ y Venezuela ${ }^{14-18}$.

La mayoría de estos estudios se han realizado en poblaciones urbanas, pero poco se conoce sobre la prevalencia de la infección en la población rural $^{4} \mathrm{y}$, con la excepción de algunas investigaciones realizadas en Brasil 7,19,20, Ecuador ${ }^{21}$ y Panamá ${ }^{9}$, es escasa la información sobre la prevalencia de toxoplasmosis en las comunidades indígenas.

En Venezuela en áreas urbanas el porcentaje de prevalencia comunicado oscila entre 31,8 y $61 \%$ en mujeres embarazadas ${ }^{13,14}, 41,8$ y $53,5 \%$ en individuos entre 0 y 60 años $15,16,57,6$ y 66,7\% en niños menores de 15 años $^{16,17}$, y 36,6\% en individuos de zonas marginales ${ }^{18}$. En áreas rurales, el porcentaje de seropositividad es de 39\% en soldados de 18-20 años ${ }^{13}$ y 49,3\% en individuos de 0-60 años ${ }^{15}$. En poblaciones indígenas son muy pocos los trabajos realizados, describiéndose una prevalencia de 49,7\% en amerindios de la etnia Barí de la Sierra de Perijá del Estado Zulia ${ }^{22}$ y $88 \%$ en la etnia Guajiba de la selva amazónica venezolana ${ }^{23}$.

La prevalencia y la distribución geográfica de T gondii documentada con la que se cuenta en nuestro país son fraccionadas. Además la mayoría de los estudios se han basado en muestras de hospitales no representativas de la población.

El propósito de este estudio fue determinar la seroprevalencia de $\mathrm{T}$ gondii en una comunidad indígena Yucpa de la Sierra de Perijá, identificar los factores de riesgo presentes en la zona y definir cómo el proceso de transculturización afecta la diseminación de la infección.

\section{Población y MÉtodos}

Área y población estudiada. La Sierra de Perijá se encuentra ubicada al oeste del Estado Zulia. Forma la frontera occidental entre Colombia y Venezuela (Figura 1). Las precipitaciones son abundantes (1.500-2.400 $\left.\mathrm{mm}^{3}\right)$, con una temperatura máxima de $30^{\circ} \mathrm{C}$ y mínima de $13^{\circ} \mathrm{C}^{24,25}$.

Los Yucpa pertenecen a la familia Caribe y abarcan aproximadamente 4.174 indígenas, ubicados en aproximadamente 41 comunidades ${ }^{26}$. Tra- dicionalmente cada una de las comunidades ha ocupado un territorio diferente, orientado siempre hacia un valle fluvial particular. La población está repartida en asentamientos pequeños disper$\operatorname{sos}^{24,25}$. Este estudio fue realizado en la población de la comunidad Yucpa de Maraca.

Debido a la confiscación de los antiguos terrenos de caza, ahora propiedad de haciendas privadas, la alimentación es básicamente de tipo vegetal, con un escaso consumo de carnes. La poca carne que se consume es bien cocida ${ }^{27}$.

La mayonía de las viviendas en la comunidad estudiada están distribuidas linealmente, una al lado de la otra y de frente al camino principal, construidas con paredes de bloques, techos de zinc y pisos de cemento, con una arquitectura tipo vivienda rural, mientras que otras, una minoría, están distribuidas en forma desordenada y siguen el estilo de la vivienda típica indígena Yucpa, las cuales carecen de

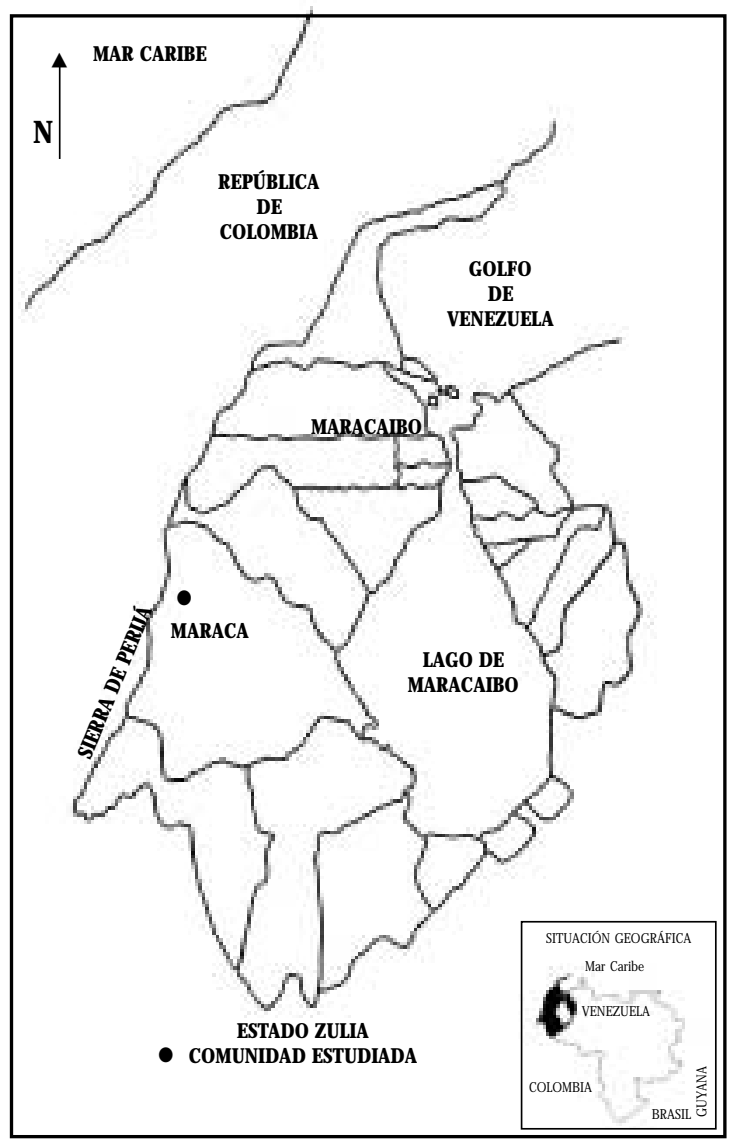

Figura 1. Mapa que indica la localización geográfica de la comunidad indígena Yucpa estudiada. 
paredes, piso y tienen solamente un techo construido con hojas de plátano. El número de personas que viven en cada casa vańa entre 5 y 12.

La población presenta precarias condiciones sanitarias, hay electricidad pero carecen de sistemas para la disposición de excretas y de desechos, no hay agua potable, el agua para consumo se obtiene directamente del río (el Palmar o Tokuko) y la almacenan en recipientes sin tapa. No hay servicios de asistencia médica.

Existen en el poblado diversos animales domésticos como: gatos, perros, cerdos, gallinas, patos, vacas, caballos, mulos, etc. Los gatos son numerosos, carecen de dueño y deambulan libremente por la comunidad, visitan numerosas casas en sus recorridos y realizan la deposición de sus excrementos en los alrededores de las viviendas de tipo rural, mientras que en las viviendas típicas defecan no sólo en sus alrededores sino también en el interior de las mismas. La calle del pueblo es paso frecuente del ganado de las haciendas de los alrededores, lo cual representa un factor de diseminación de parásitos en la comunidad.

La comunidad Yucpa de Maraca estaba formada, para el momento de la investigación, por 110 habitantes de uno u otro sexo, con edades comprendidas entre 3 meses a 100 años, siendo estudiados 85,4\% (94/110, 49 del sexo femenino y 45 del sexo masculino) del total de la población. Esta comunidad conforma un ambiente socio-cultural muy específico por lo que fue escogida para este estudio epidemiológico como patrón de medida de las enfermedades parasitarias en las diversas comunidades indígenas que pueblan el noroeste de Venezuela.

Recolección de los datos. Se les explicó a la comunidad de Maraca el objetivo del estudio y se obtuvo el consentimiento de cada uno de los individuos o de sus representantes, para el caso de los menores de edad, antes de su inclusión en el mismo. Se practicó una encuesta con la finalidad de recoger información básica como: edad, sexo y ocupación. No fue posible recoger datos sobre el número de gatos domésticos, ya que estos animales no tienen dueño y deambulan libremente, sin embargo durante la estadía en la comunidad se observó un elevado grupo de ellos tanto en el interior como en los alrededores de las viviendas. Esta investigación fue aprobada por el Comité de Ética de la Universidad del Zulia.
Metodología de laboratorio. Las muestras de sangre fueron obtenidas por punción venosa $\mathrm{y}$ centrifugadas a $2.500 \mathrm{rpm}$ por $5 \mathrm{~min}$. Los sueros así obtenidos fueron congelados a $-20^{\circ} \mathrm{C}$ hasta el momento de ser procesados. La determinación de anticuerpos totales se realizó a través de la técnica de hemaglutinación indirecta (HAI) (Toxotest HAI Wiener Lab), y la determinación de anticuerpos IgM a través de la técnica de ELSA (ETI-TOXOK$M$ reverse PLUS. DiaSorin SRL). Para HAI se consideró como reacción positiva diluciones superiores a 1:64.

Análisis estadístico. Los datos fueron expresados en distribución de frecuencias. Para determinar diferencias significativas entre los grupos estudiados se realizó la prueba de Chi-cuadrado y el análisis exacto de Fischer, según correspondiera. Para definir relación entre las variables estudiadas se realizó el análisis de correlación de Spearman. Se tomó el 95\% como índice de confiabilidad estadística. Se consideró significativa toda probabilidad menor al 0,05.

\section{Resultados}

La Tabla 1 muestra la distribución de anticuerpos totales y anticuerpos de tipo IgM en la población estudiada. El porcentaje general de positividad para anticuerpos totales fue $62,7 \%(59 / 94)$ y $23,7 \%$ (14/59) para IgM. Los mayores porcentajes de prevalencia de anticuerpos totales se observaron en los individuos mayores de 41 años $(77,7 \%)$, en tanto que para los anticuerpos de tipo IgM el mayor porcentaje fue en los individuos menores de 20 años (30,3\%). El total de la media geométrica del título (MGT) fue de 3.354, siendo más elevada en el grupo etario de 21 a 30 años.

La Tabla 2 representa la distribución de anticuerpos totales anti $\mathrm{T}$ gondii según sexo y grupo etario, el mayor porcentaje de seropositividad se observó en el grupo etario de 41 a 50 años para ambos sexos. No se evidenció asociación significativa entre la edad y el sexo, y el grado de positividad para la infección.

La Tabla 3 muestra la distribución de anticuerpos IgM anti T gondii según sexo y grupo etario. El mayor porcentaje de seropositividad se observó en el grupo etario menor de 20 años (10/33) para 
Tabla 1. D istribución de anticuerpos totales y anticuerpos IgM anti T gondii según el grupo etario

\begin{tabular}{|lcccrr|}
\hline $\begin{array}{l}\text { Grupo } \\
\text { etario }\end{array}$ & Anticuerpos totales & \multicolumn{2}{c|}{ IgM } & \\
\cline { 2 - 5 } & Positivos/Examinados & $\%$ & Positivos/Examinados & $\%$ & MGT \\
\hline $0-10$ & $19 / 35$ & 54,9 & $6 / 19$ & 31,5 & 2.458 \\
$11-20$ & $14 / 25$ & 56,0 & $4 / 14$ & 28,5 & 11.590 \\
$21-30$ & $5 / 7$ & 71,4 & $2 / 5$ & 40,0 & 16.390 \\
$31-40$ & $7 / 9$ & 77,7 & $0 / 7$ & - & 1.855 \\
$41-50$ & $8 / 10$ & 80,0 & $1 / 8$ & 12,5 & 861 \\
$>50$ & $6 / 8$ & 75,0 & $1 / 6$ & 16,6 & 1.625 \\
\hline Total & $59 / 94$ & 62,7 & $14 / 59$ & 23,7 & 3.354 \\
\hline
\end{tabular}

Tabla 2. D istribución de anticuerpos totales anti T gondii según sexo y grupo etario

\begin{tabular}{|lcccccc|}
\hline $\begin{array}{l}\text { Grupo } \\
\text { etario }\end{array}$ & Masculinos & \multicolumn{3}{c|}{ Femeninos } & Total & $\%$ \\
\cline { 2 - 5 } & Positivos/Examinados & $\%$ & Positivos/Examinados & $\%$ & & 54,2 \\
$0-10$ & $8 / 19$ & 42,1 & $11 / 16$ & 68,7 & $19 / 35$ & 56,0 \\
$11-20$ & $6 / 11$ & 54,5 & $8 / 14$ & 57,1 & $14 / 25$ & 71,4 \\
$21-30$ & $4 / 6$ & 66,6 & $1 / 1$ & 100,0 & $5 / 7$ & 77,7 \\
$31-40$ & $3 / 5$ & 60,0 & $4 / 4$ & 100,0 & $7 / 9$ & 80,0 \\
$41-50$ & $3 / 3$ & 100,0 & $5 / 7$ & 71,4 & $8 / 10$ & 75,0 \\
$>50$ & $3 / 5$ & 60,0 & $3 / 3$ & 100,0 & $6 / 8$ & 62,7 \\
\hline Total & $27 / 49$ & 55,1 & $32 / 45$ & 71,1 & $59 / 94$ & \\
\hline
\end{tabular}

Tabla 3. D istribución de anticuerpos IgM anti T gondii según sexo y grupo etario

\begin{tabular}{|lcccccc|}
\hline \multirow{2}{*}{$\begin{array}{l}\text { Grupo } \\
\text { etario }\end{array}$} & \multicolumn{2}{c}{ Masculinos } & \multicolumn{2}{c|}{ Femeninos } & \\
\hline & Positivos/Examinados & $\%$ & Positivos/Examinados & $\%$ & Total & $\%$ \\
\hline $0-10$ & $2 / 8$ & 25,0 & $4 / 11$ & 36,3 & $6 / 19$ & 31,5 \\
$11-20$ & $2 / 6$ & 33,3 & $2 / 8$ & 25,0 & $4 / 14$ & 28,5 \\
$21-30$ & $1 / 4$ & 25,0 & $1 / 1$ & 100,0 & $2 / 5$ & 40,0 \\
$31-40$ & $0 / 3$ & - & $0 / 4$ & - & $0 / 7$ & - \\
$41-50$ & $0 / 3$ & - & $1 / 5$ & 20,0 & $1 / 8$ & 12,5 \\
$>50$ & $1 / 3$ & 33,3 & $0 / 3$ & - & $1 / 6$ & 16,6 \\
\hline Total & $6 / 27$ & 22,2 & $8 / 32$ & 25,0 & $14 / 59$ & 23,7 \\
\hline
\end{tabular}

ambos sexos. No se evidenció diferencias significativas entre los grupos estudiados.

La distribución de títulos de anticuerpos totales se representa en la Tabla 4, 27,1\% (16/59) presentó títulos bajos (1:64-1:512), 28,8\% (17/59) presen- tó títulos altos (1:1.024-1:2.046), mientras que el mayor porcentaje $44,2 \%(26 / 59)$ fue de títulos considerados muy altos $(\geq 1: 8.192)$. El título más alto encontrado fue $1: 131.082$ en $3,4 \%(2 / 59)$ y el más bajo (1:64) en 5,1\% (3/59). 
Tabla 4. Frecuencia de títulos de anticuerpos anti Toxoplasma gondii

\begin{tabular}{|lrr|}
\hline Títulos & $\mathrm{n}$ & $\%$ \\
\hline $1: 64$ & 3 & 5,1 \\
$1: 128$ & 3 & 5,1 \\
$1: 256$ & 2 & 3,4 \\
$1: 512$ & 8 & 13,5 \\
$1: 1.024$ & 3 & 5,1 \\
$1: 2.048$ & 10 & 16,9 \\
$1: 4.096$ & 4 & 6,8 \\
$\geq 1: 8.192$ & 26 & 44,1 \\
\hline Total & 59 & 99,9 \\
\hline
\end{tabular}

La Figura 2 representa la comparación de las regresiones lineales de los datos de diversos estudios realizados en América, podemos apreciar que en países como Colombia, Costa Rica, USA y la Isla de Guadalupe $^{34}$ el porcentaje de positivos disminuye a medida que aumentan los títulos de anticuerpos, mientras que en nuestro estudio el porcentaje de positivos se mantiene, siendo similar en todas las titulaciones utilizadas.

\section{Discusión}

La distribución de las prevalencias en la población estudiada indica que la infección por T gondii es endémica en esta población indígena, y que un alto porcentaje de las infecciones primarias ocurre en edades tempranas de la vida. Esta distribución y las condiciones ambientales son similares a las observadas en muchas poblaciones de Venezuela. La prevalencia general de anticuerpos totales $(62,7 \%)$ de la comunidad estudiada fue más alta que la encontrada en poblaciones urbanas ${ }^{15,16}$ y rurales $^{15}$, similar a la reportada en algunas comunidades indígenas de etnia Barí residentes en la tierras altas de la Sierra de Perijá del Estado Zulia $(62,4 \%)^{22}$ y más baja que la reportada en indios Guajibos del Estado Amazonas (88\%) ${ }^{23}$.

El porcentaje de seroprevalencia observado fue mayor que el reportado en otros países latinoamericanos $^{6,8,10,12,28,29}$, pero similar al rango (30-100\%)

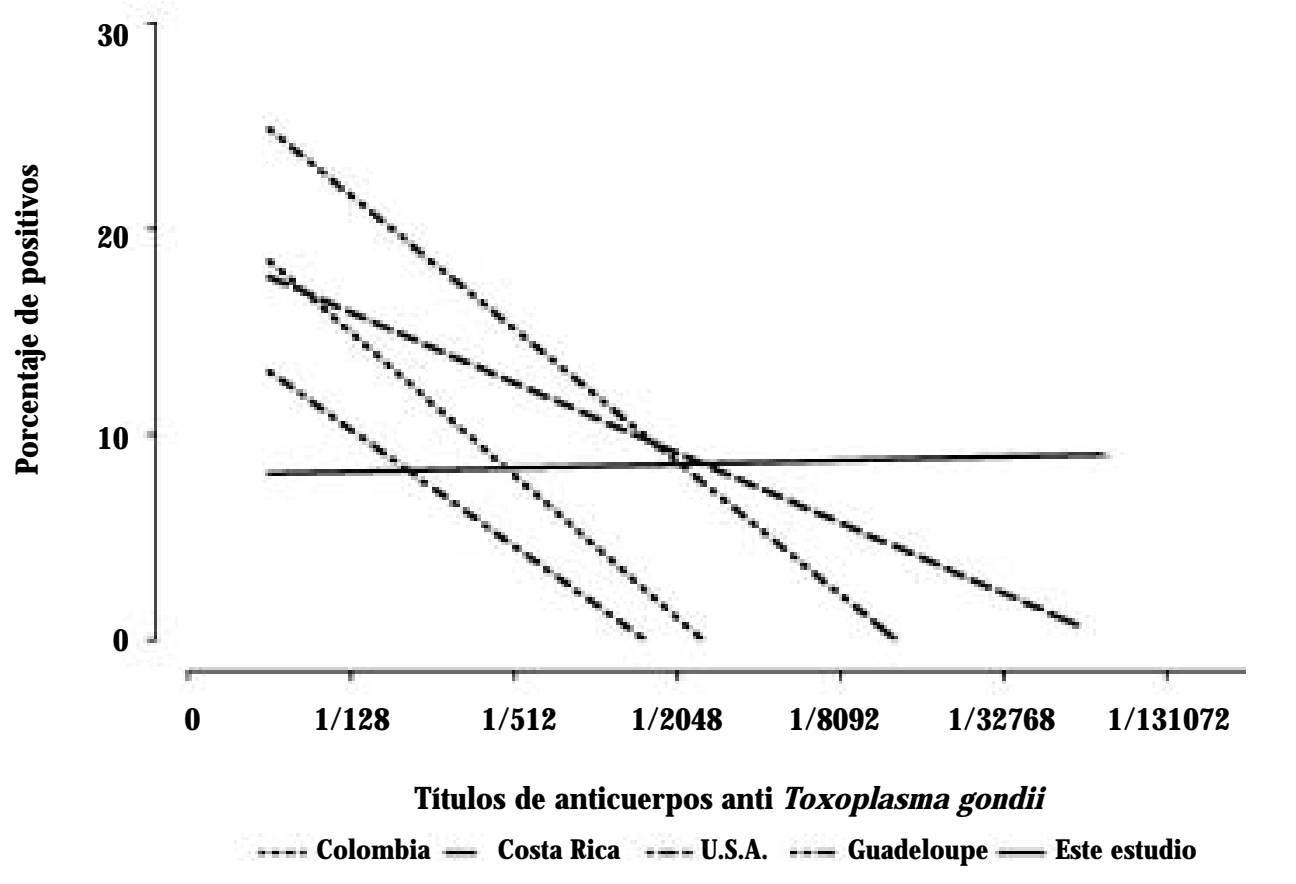

Figura 2. Regresiones lineales del porcentaje de títulos de anticuerpos totales contra el Toxoplasma gondii determinados en estudios realizados en diversos países de América34. 
comunicado en muchas comunidades selváticas de Brasil $^{7,19,20,30-32}$. Sin embargo, fue superior al observado en niños indígenas de Panamá $(0-42 \%)^{9} \mathrm{y}$ en aborígenes de Taiwán (15,9-17,2\%) ${ }^{33}$.

Una pequeña proporción de individuos reactivos $(13,5 \%)$ presentó títulos de anticuerpos totales bajos (1:64-1:256), mientras que la mayoría de los individuos positivos $(72,8 \%)$ presentaron títulos altos $(\geq 1: 1.024)$ sugestivos de enfermedad reciente o activa, o de una alta frecuencia de reinfección. Estos hallazgos y la presencia de títulos elevados en los grupos de menor edad no es sorprendente ya que $42,5 \%$ de la población estudiada fue $\leq 12$ años y se ha comunicado un alto grado de seroconversión temprana en niños latinoamericanos $^{4,10,34}$. La presencia de títulos de anticuerpos totales altos en tales grupos de edad puede estar relacionada con una exposición temprana al parásito $^{4}$ y se corrobora por el alto porcentaje de IgM positiva en estos mismos grupos.

De las diferentes formas de transmisión de $\mathrm{T}$ gondii, heces de gatos infectados, ingestión de carne o sus derivados insuficientemente cocidos y contaminados con quistes, y por vía transplacentaria, la primera parece jugar un papel predominante en la diseminación de infecciones humanas tanto en estas comunidades indígenas, como en otras áreas de Latinoamérica ${ }^{10,28}$. Sus actividades agrícolas y las malas condiciones de higiene sugiere un contacto frecuente con la tierra. De hecho, el alto porcentaje de infección $(84,6 \%)$ con uno o más parásitos intestinales incluyendo helmintos, encontrados en esta comunidad (observaciones no publicadas), es una clara evidencia del contacto con tierra. La segunda forma de transmisión juega aparentemente un rol insignificante, si es que alguno, ya que la dieta de estos indígenas está conformada básicamente por tubérculos y la poca carne ingerida es bien cocida. Debe considerarse igualmente, para el ciclo de infección por $\mathrm{T}$ gondii, que bajo condiciones selváticas la participación de felinos salvajes es frecuente ${ }^{35,36}$. Así, la ingestión de agua contaminada con los ooquistes expulsados por los gatos y felinos salvajes ${ }^{37}$ y la presencia de roedores salvajes, que actúan como huéspedes intermediarios persistentes ${ }^{38}$, son factores de riesgo importantes ya que en estas comunidades indígenas el uso de fuentes de agua comunes en recipientes abiertos puede conducir a la diseminación de la infección a través del agua.
En Panamá el agua ha sido implicada como un modo de transmisión epidémica y endémica en soldados $^{39}$ y en niños indígenas ${ }^{9}$.

El estilo de vida sedentario de estos indígenas ha sido trastornado al circunscribir sus actividades agrícolas, de vivienda y esparcimiento en áreas progresivamente más pequeñas, debido al establecimiento de granjas agrícolas y haciendas de ganado. Igualmente su tipo de hábitat ha sido transformado al sustituir los pisos de tierra de las viviendas típicas en los pisos de concreto de la mayoría de las viviendas rurales. Todos estos cambios probablemente han limitado la disponibilidad de suelos para la defecación de los gatos y otros animales domésticos, concentrando esta actividad en áreas cercanas a las viviendas y en los escasos campos de cultivo ${ }^{10}$. Este proceso incrementa la densidad de los ooquistes en los suelos, según se sugiere por estudios previos $^{28}$, provocando un aumento del riesgo de contacto con los mismos y por ende del porcentaje de transmisión de $\mathrm{T}$ gondii.

No se observó asociación significativa entre la edad y la presencia de anticuerpos, lo que sugiere contaminación constante de los individuos sin relación con la edad. Igual conclusión puede inferirse de la observación de la Figura 2, en donde el porcentaje de positividad no disminuye con el incremento de los títulos, distribución muy diferente a la comunicada por otros estudios. Sin embargo, el mayor porcentaje de prevalencia lo observamos en el grupo etario de 010 años $(54,2 \%)$, esta alta proporción de infecciones en estos niños puede estar relacionada con sus actividades de juego en áreas con suelos contaminados lo que conlleva a un amplio contacto con el suelo, incrementando la posibilidad de adquinir la infección por el T gondii $4,10,31$.

En cuanto a la transmisión vertical por vía placentaria, es muy probable que ocurra en esta comunidad, en función del alto porcentaje de positividad observado en los grupos de mujeres en edad fértil. Sin embargo, no fue propósito de este estudio definir esa variable, necesitándose posteriores estudios longitudinales que determinen la importancia de esta forma de transmisión.

Los indígenas son un grupo vulnerable a las enfermedades emergentes debido a la confluencia de varios factores: labilidad inmunológica, carencia de servicios de atención médica, deficiente saneamiento ambiental y poca o ninguna medida preventiva. En estas comunidades existe un alto porcentaje 
de morbimortalidad como de reacciones inusuales ante agentes patógenos que son frecuentemente inofensivos para los no indígenas. Se conoce el efecto devastador que producen en estas comunidades enfermedades como tuberculosis, malaria, enfermedad de Chagas, hepatitis, sarampión, infección por el virus de inmunodeficiencia adquirida humana y otras enfermedades infecciosas. Hadler y cols $^{40}$ en 1984 comunicaron una posible epidemia de hepatitis $B$, posteriormente se determinó que muchos de los pacientes presentaron una evolución clínica fulminante atribuyéndose este fenómeno a virus Delta de la hepatitis.

Este estudio determinó cómo el porcentaje de transmisión de toxoplasmosis se ha incrementado entre los indígenas Yucpas por los cambios

\section{REFERENCIAS}

1. Atias A. Toxoplasmosis. En: Parasitología Clínica. Santiago: Editorial Publicaciones Técnicas Mediterráneo, 1991; 270-83.

2. García JL, Navarro it, Ogawa L, De Oldveira RC, KoвiLKa E. Soroprevalência, epidemilogía e avaliaçao ocular da toxoplasmose humana na zona rural de Jaguapita (Paraná) Brasil. Rev Panam Salud Publica 1999; 6: 157-63.

3. Botero D, Restrepo M. Toxoplasmosis. En: Parasitosis Humanas. Medellín: Editorial Corporación para Investigaciones Biológicas, 1998; 252-70.

4. Sousa OE, Saenz RE, Frenkel JK. Toxoplasma in Panama: a 10 years study. Am J Trop Med Hyg 1988; 38: 315-22.

5. Schenone H, Contreras MC, Salinas P, Sandoval L, Peña AM, Rodríguez H et AL. Epidemiología de la toxoplasmosis en Chile. I. Prevalencia de la infección humana, estudiada mediante la reacción de hemaglutinación indirecta, en las tres primeras regiones. 1982-1985. Bol Chil Parasitol 1987; 41: 36-9.

6. Contreras M, Schenone H, Salinas P, Sandoval L, Rojas A, Viliarroel F et al. Seroepidemiology of human toxoplasmosis in Chile. Rev Inst Med Trop Sao Paulo 1997; 38: 431-5.

7. Baruzzi RG. Contribution to the study of toxoplasmosis epidemiology. Serologic survey among the indians of the upper Xingu River, Central Brazil. Rev Inst Med Trop Sao Paulo 1971; 12: 93-104.

8. FRenKel J, Lazo R, Lazo J. Encuesta sobre infección toxoplásmica en un grupo de alumnos del tercer año de medicina y en un número igual de gatos, socioculturales. En efecto, debido a la permanente limitación de su hábitat y la pérdida de sus costumbres ancestrales han sufrido cambios en su patrón de asentamiento, reagrupándose en núcleos poblados más grandes, incrementándose el uso de fuentes de agua comunes, acentuándose el modo de vida sedentario, lo cual está relacionado de forma directa con la transmisión de este tipo de enfermedad. La alta prevalencia de toxoplasmosis observada supone un riesgo considerable para la supervivencia de estas etnias indígenas. Una adecuada educación sanitaria, así como la adopción de medidas tendientes a mejorar las condiciones de higiene y saneamiento básicos, son factores relevantes en el control de esta enfermedad.

de la ciudad de Guayaquil. Rev Med Trop Parasitol 1984; 1: 17-22.

9. Etherege GD, FrenKel JK. Human Toxoplasma infection in Kuna and Embera children in the Bayano and San Blas, eastern Panama. Am J Trop Med Hyg 1995; 53: 448-57.

10. Frenkel JK, Ruiz A. Human toxoplasmosis and cat contact in Costa Rica. Am J Trop Med Hyg 1981; 29: 1167-80.

11. Veiasco-Castrejón O, Salvatierra-Izaba B, Valdespino JL, Sedano-Lara AM, Gaundo-Virgen S, Magos C et AL. Seroepidemiología de la toxoplasmosis en México. Salud Pública Mex 1992; 34: 222-9.

12. Martínez Sánchez R, Machin Sánchez R, Suarez Hernández M, Fachado Carvajales A. Aspectos seroepidemiológicos de la toxoplasmosis en 2 municipios de la provincia de Ciego de Avila. Septiembre 1985. Rev Cubana Med Trop 1991; 41: 214-25.

13. MAekelt GA, Gómez Z. Primeras experiencias con la prueba de Sabin-Feldman para el diagnóstico de la toxoplasmosis. Arch Venez Med Trop Parasitol Med 1962; 4: 265-75.

14. Figalo L, Maekelt GA. Anticuerpos de toxoplasmosis en parturientas y recién nacidos de la maternidad "Concepción Palacios" de Caracas, Venezuela. Arch Venez Med Trop Parasitol Med 1962; 4: 289-99.

15. SerRano H. Estudios sobre la incidencia de anticuerpos séricos para Toxoplasma en las poblaciones de Maracaibo y un pueblo rural del Estado Zulia y comparación de tres métodos serológicos distintos. Kasmera 1974; 5: 75-101.

16. Bonfante-Garrido R, De Alvarez NM, De Anzola NH, De 
Crespo LR, Bonfante Cabarcas R, De Peñaloza SC. Toxoplasmosis en pacientes de 14 estados de Venezuela. Bol Oficina Sanit Panam 1984; 96: 502-10.

17. Vargas de CAmino N. Títulos de anticuerpos para Toxoplasma en una población pediátrica de Maracaibo, Venezuela. Kasmera 1982; 10: 72-81.

18. Díaz-Suárez O, Parra AM, Araujo-Fernández $\mathrm{M}$. Seroepidemiología de la toxoplasmosis en una comunidad marginal del Municipio Maracaibo, Estado Zulia, Venezuela. Invest Clin 2001; 42: 107-21.

19. Neel JV, Andrade AH, Brown GE, Eveland WE, Goobar J, Sodeman WA et aL. Further studies on the Xavante Indians IX. Immunologic status with respect to various diseases and organisms. Am J Trop Med Hyg 1968; 17: 486-98.

20. Rocha MO, Carvalho MG, Silva M, Sarmento B, Lgnani C. Remanescentes xakriabá em Minas Gerais: Prevalencia da Doenca de Chagas e Toxoplasmose e avaliacão da quadro hematológico dos infectados/xakraibá renmants in Minas Gerais. Rev Farm Bioquím 1987; 8: 19-27.

21. Kaplan JE, Larrick JW, Yost J, Farrell L, GreEnBerG HB, HERRMANN KL ET AL. Infectious disease patterns in the Waorani, an isolated Ameridian population. Am J Trop Med Hyg 1980; 29: 298-312.

22. Chacin-Bonilla L, Sánchez-Chávez Y, Monsalve F, ESTEVEZ J. Seroepidemiology of toxoplasmosis in amerindians from western Venezuela. Am J Trop Med Hyg 2001; 65: 131-5.

23. De la Rosa M, Bolívar J, Pérez HA. Infección por Toxoplasma gondii en amerindios de la Selva Amazónica de Venezuela. Medicina (B Aires) 2000; 59: 759-62.

24. Fundación La Salle: Aborígenes de Venezuela. Tomo I. Etnología Contemporánea. 1983; 335.

25. Fundación La Salle: Aborígenes de Venezuela. Tomo II. Etnología Contemporánea. 1983; 124.

26. Oficina Central de Estadística e Informática (OCEI). 1993 Censo Indígena de Venezuela 1992, Tomo I. Caracas.

27. Derjani M. Características de la dieta diaria de los Yukpas. Holmes R, Velásquez T. Estado de Salud Indígena, Los Yukpa. Maracaibo, Venezuela: Fundación Zumaque; 1994; 62-75.

28. Frenkel JK, Ruiz A. Endemicity of toxoplasmosis in Costa Rica. Am J Epidemiol 1981; 113: 254-69.

29. Frenkel JK, Ruiz A, Chinchila M. Soil survival of Toxoplasma oocysts in Kansas and Costa Rica. Am J Trop Med Hyg 1975; 24: 439-43.

30. Lovelace JK, Moraes MA, Hagerby E. Toxoplasmosis among Ticuna Indians in the state of Amazonas, Brazil. Trop Geogr Med 1979; 30: 295-300.

31. Ferraroni JJ, De Almeida Marzochi MC. Prevalencia da infeccao pelo Toxoplasma gondii em animais domésticos, silvestres e grupamentos da Amazonia. Mem Inst Oswaldo Cruz 1981; 75: 99-109.

32. Ferraroni JJ, Lacaz CS. Prevalencia de anticorpos contra os agentes causadores da hepatite, malaria, sífilis e toxoplasmose em cinco populacoes humanas disintas da Amazonia Brasileira. Rev Inst Med Trop Sao Paulo 1982; 24: 155-61.

33. Fan CK, Su KE, Chung WC, Tsai YJ, Chiol HY, Lin CF ET AL. Seroepidemiology of Toxoplasma gondii infection among Atayal aborigines and local animals in Nan-ao district, Ilan county and Jen-ai district, Nan-tou county, Taiwan. Kaohsiung J Med Sci 1998; 14: 762-9.

34. Barbier D, Ancele T, Martin-Bouyer G. Seroepidemiological survey of toxoplasmosis in La Guadeloupe, French West Indies. Am J Med Trop Hyg 1983; 32: 935-42.

35. Jewell ML, FRENKel JK, Johnson KM, ReEd V, Ruiz A. Development of Toxoplasma oocysts in neotropical Felidae. Am J Trop Med Hyg 1972; 21: 512-7.

36. Aramini JJ, Stephen C, Dubey JP. Toxoplasma gondii in Vancouver Island cougars (Felis concolor vancouverensis): serology and oocyst shedding. J Parasitol 1998; 84: 438-40.

37. Bowie WR, KIng AS, Werker DH, IsAac-Renton JL, BeiL A, ENG SB ET AL. Outbreak of toxoplasmosis associated with municipal drinking water. The BC Toxoplasma Investigation Team. Lancet 1997; 350: 173-7.

38. Webster JP. Prevalence and transmission of Toxoplasma gondii in wild brown rats, Rattus norvegicus. Parasitology 1994; 108: 407-11.

39. Benenson MW, Takafuji ET, Lemon SM, Greenup RL, Sulzer AJ. Oocysts-transmitted toxoplasmosis associated with ingestion of contaminated water. N Engl J Med 1982; 307: 666-9.

40. Hadier SC, Monzon M, Ponzetto A, Anzola E, Rivero D, Mondolfi A ET AL. Delta virus infection and severe hepatitis. An epidemic in the Yucpa Indians of Venezuela. Ann Intern Med 1984; 100: 339-44.

\section{Agradecimientos}

Agradecemos la amplia colaboración de la comunidad indígena Yucpa las Maracas que permitió la realización de este estudio. Igualmente a los misioneros Jackelin y Braulio por apoyo desinteresado. 